$15^{\text {th }}$ International Conference on

AEROSPACE SCIENCES \& AVIATION TECHNOLOGY,

$\boldsymbol{A S A T}$ - 15 - May 28 - 30, 2013, Email: asat@mtc.edu.eg,

Military Technical College, Kobry Elkobbah, Cairo, Egypt,

Tel: +(202) 24025292-24036138, Fax: +(202) 22621908

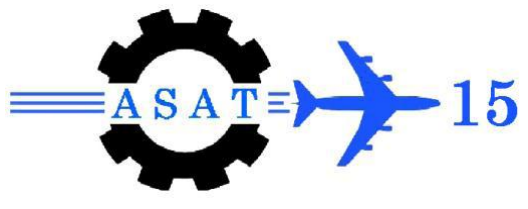

\title{
UAV Mathematical Modeling, Analysis and Fuzzy Controller Design
}

\author{
A. B. El-Demerdash ${ }^{*}$, M. M. El-khatib ${ }^{\dagger}$, W. M. Hussein ${ }^{\dagger}$ and Y. Hendawy ${ }^{\dagger}$
}

\begin{abstract}
The objective of this work is to introduce the design, simulation and control of a quad rotor, equipped with Inertial Sensors, as an example of unmanned aerial vehicle. To fulfill this objective a mathematical model of the quad rotor has been developed, using Newton-Euler Formulation. The simulation of the model and controller design is developed in MATLAB/Simulink environment. It is intended to make the model flexible and easily modified to be used with any similar model. In order to evaluate the real model mass and mass moment of inertia, a solid model had been built using Autodesk Inventor software package. To validate the proposed model output results, a comparison with published research has been carried out which showed a good agreement. Finally, a fuzzy controller is designed to control the quad rotor altitude and the three Euler angles of roll, pitch and yaw. The controller showed a good controllability within a certain range of the controlled parameter.
\end{abstract}

Keywords: UAV, nonlinear control, PID like fuzzy controller.

\section{Introduction}

Unmanned aerial vehicles (UAV) are proven to be useful for many military and civil applications. The most important features are vertical take-off and landing (VTOL) and hover capability, so it is suited for missions such as video inspection of buildings for maintenance, road traffic supervision, victims localization after natural disasters, etc. Such vehicles have also received a growing interest from academic research institutes, since they can be used as low cost test beds for robotic studies[1],[2],[3].

To make autonomous flight of UAVs possible, control laws must be developed to replace the action of a human pilot. Linear control techniques such as PID or LQR have been applied to solve this problem[4]. Input-output linearization is one of the nonlinear control schemes that have been proposed for rotary wings UAVs. Since that method can only be applied to minimum phase systems, and since, generally, helicopters have unstable zero dynamics, an approximate input-output linearization has been proposed in [5]. Another solution consists in the application of back stepping techniques, by considering the model used for control design as a chain of integrators. Back stepping has been widely applied to different UAV vehicles such as conventional helicopters[6], [7], coaxial bi-rotor helicopters [8] or four-rotor vehicles [4].

Egyptian Armed Forces, Egypt; bahgatdd@yahoo.com .

$\dagger$ Egyptian Armed Forces, Egypt.

* Professor, $10^{\text {th }}$ of Ramadan Higher Institute, Egypt. 
In order to understand and study the behavior of systems, mathematical models are needed. These models are equations which describe the relationship between the inputs and outputs of the system. They can be used to enable forecasts to be made of the behavior of the system under specific conditions and to simulate the system under study in order to examine the proposed controller. The introduced mathematical model is based on deriving the equation of motion for a rigid air craft.

Linear models such as the one introduced in equations (1), (2) have been used extensively in the past and the control theory for linear systems is quite mature.

$$
\begin{aligned}
& \dot{X}=A X+B U \\
& Y=C X+D U
\end{aligned}
$$

where:

$$
\begin{array}{ll}
X \ldots(n \times 1) & \text { the state vector } \\
U \ldots(m \times 1) & \text { the control vector } \\
\text { Y } \ldots(p \times 1) & \text { the output vector }
\end{array}
$$

A, B, C, D matrices of appropriate dimension.

In our case, the system is a nonlinear one, where the equations of motion are expressed in the state-space form as [9]:

where:

$$
\dot{\mathrm{X}}=\mathrm{f}(\mathrm{X}, \mathrm{U})
$$

$$
\begin{array}{ll}
X \ldots(n \times 1) & \text { the state vector } \\
\mathrm{U} \ldots(\mathrm{m} \times 1) & \begin{array}{l}
\text { the control vector } \\
\mathrm{f}(,, \ldots, \ldots)
\end{array} \\
& \begin{array}{l}
\text { vector valued nonlinear function of the individual states and } \\
\text { controls. }
\end{array}
\end{array}
$$

The state of a system is defined as an indication of the stored energy in that system ( i.e., potential and kinetic energy) and its distribution which is completely defined by the state variables $X_{i}$.

Also the output equation is required in the general form:

where:

$$
\mathrm{Y}=\mathrm{g}(\mathrm{X}, \mathrm{U})
$$

$$
\begin{array}{ll}
\mathrm{Y} \ldots(p \times 1) & \text { the output vector } \\
\mathrm{g}(,,, \ldots) \ldots & \text { a set of nonlinear equations similar to } \mathrm{f} .
\end{array}
$$

while the output variable $Y_{i}$ corresponds to the provided measured quantities from the onboard $i^{\text {th }}$ sensor.

The equations of motion of a rigid body can be decoupled into rotational equations and translational equations when taking the origin coordinate to be at the center of mass (center of gravity) of the rigid body[9],[10]. The state model derived later will be 6-Degrees Of Freedom model, three of which are the rotational motion of the rigid body about the coordinate axis which are fixed to the body center of gravity (yaw, pitch, and roll), and the other will be the three components of translation of the cg (Figure 1). 


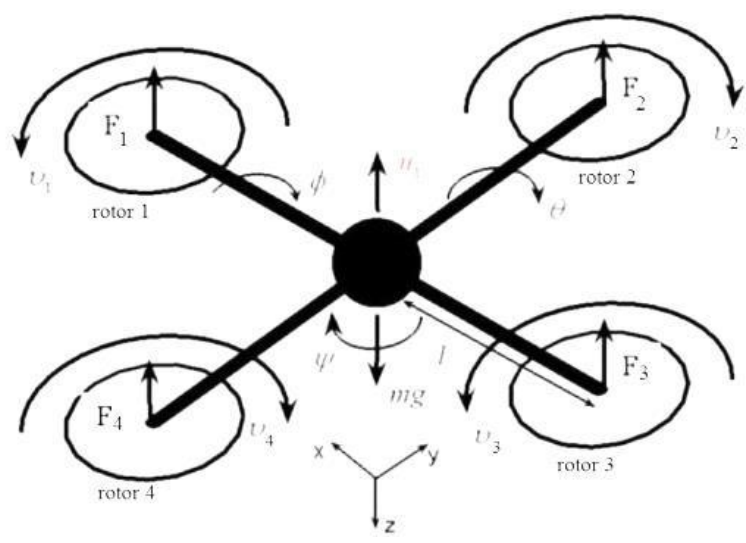

Fig. 1. Body Fixed coordinate and Flat Earth coordinate

The state vector $\mathbf{X}$ of the proposed model consists of 12 state variables. The first set is the three components of position which specify the potential energy. Translational kinetic energy is represented by the three components of velocity; however the rotational kinetic energy is introduced by the three components of angular velocity. The last set is the attitude state, which defines the orientation relative to the gravity vector.

\section{Mathematical Model Formulation}

In the derivation of the UAV equations of motion starting from the Newton's second law of motion, two coordinate systems are introduced. The first is the inertial coordinate $\mathbf{O}$ attached to the Earth frame at earth's mass center passing through north pole and stationary with respect to the fixed stars where Newton's laws of motion are valid(within the Euclidean space). The second coordinate is placed at the center of gravity of the UAV while flying and it has a fixed alignment to some convenient reference line of the UAV.

Assuming that the proposed system is flying near the earth surface and the air rotate with earth (the earth rotation effect is neglected), the inertial coordinate is replaced by Flat Earth coordinate $\mathbf{E}$ at the surface of the earth (i.e. the observer) as shown in Figure (2) with $\mathrm{x}$-axis pointing to north and $\mathrm{z}$-axis pointing downward.

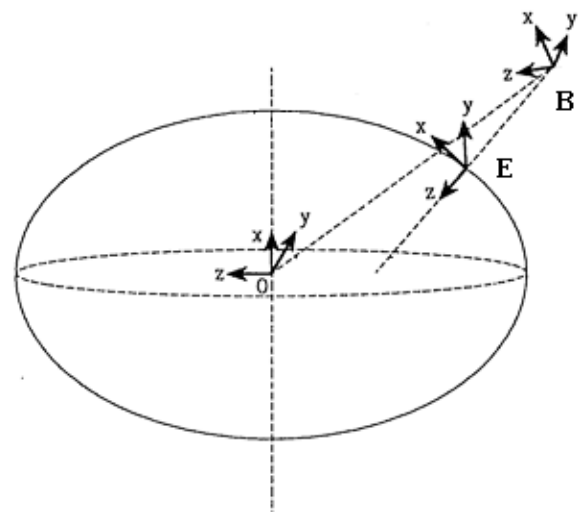

Fig. 2. The inertial, flat earth, and body coordinate representation

The model equations can be divided into two sets, the first set is the navigation equations derived from kinematics of rigid bodies[9], and the second set is the equations of motion derived from Newton's laws[10]. 


\subsection{Attitude Equation}

The rotation of the inertial frame to the body centered frame (aligned as $\mathrm{x}$-forward, $\mathrm{y}$ starboard, and z-down in the UAV) which describes the instantaneous attitude of the UAV is performed in the following sequence of rotations [10]:

i. $\quad$ Rotate about the z-axis, nose right (positive $\psi$ "yaw")

ii. Rotate about the new y-axis, nose up (positive $\theta$ "pitch")

iii. Rotate about the new $\mathrm{x}$-axis, right arm down (positive $\varphi$ "roll")

These angles are referred commonly as Euler angles, so the coordinate transformation is:

$$
\left[\begin{array}{l}
\mathrm{x} \\
\mathrm{y} \\
\mathrm{z}
\end{array}\right]_{\mathrm{B}}=\mathrm{R}_{\varnothing} \mathrm{R}_{\theta} \mathrm{R}_{\Psi}\left[\begin{array}{l}
\mathrm{x} \\
\mathrm{y} \\
\mathrm{z}
\end{array}\right]_{\mathrm{E}}
$$

Let $\mathrm{R}$ denotes the complete transformation from the flat earth coordinate to the body coordinate frame as follow:

$$
\mathrm{R}=\mathrm{R}_{\varnothing} \mathrm{R}_{\theta} \mathrm{R}_{\Psi}
$$

where:

$$
\mathrm{R}=\left[\begin{array}{ccc}
\cos \theta \cos \psi & \cos \theta \sin \psi & -\sin \theta \\
-\cos \phi \sin \psi+\sin \phi \sin \theta \cos \psi & \cos \phi \cos \psi+\sin \phi \sin \theta \sin \psi & \sin \phi \cos \theta \\
\sin \phi \sin \psi+\cos \phi \sin \theta \cos \psi & -\sin \phi \cos \psi+\cos \phi \sin \theta \sin \psi & \cos \phi \cos \theta
\end{array}\right]
$$

The matrix $\mathrm{R}$ describes the attitude of the UAV as it changes with time. Its elements are functions of the Euler angles $\phi, \theta$, and $\psi$.

From the above analysis; the matrix $\mathrm{R}$ describes the transformation from the flat earth coordinate to the UAV body cg coordinate so:

$$
\mathrm{v}_{\mathrm{B}}=\mathrm{R} \mathrm{v}_{\mathrm{E}}
$$

where:

$\mathbf{v}_{\mathbf{B}} \ldots$ absolute velocity vector of the UAV cg expressed in body frame.

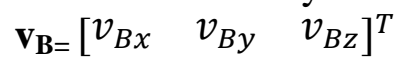

$\mathbf{v}_{\mathbf{E}} \ldots$ absolute velocity vector of the UAV cg expressed in inertial frame.

In the Flat earth coordinate, let the position vector of the UAV cg is denoted by $p(t)$, it is convenient to write the following:

$$
\dot{\mathrm{p}}=\mathrm{R}^{\mathrm{T}} \mathrm{v}_{\mathrm{B}}
$$

where

$\mathrm{R}^{\mathrm{T}} \ldots \quad$ the transpose matrix of $\mathrm{R}$ that rotates the $\mathbf{v}_{\mathbf{B}}$ into Flat earth coordinate

The derivative of this equation with respect to the inertial frame is:

$$
\frac{d}{d t_{I}}\left(\mathrm{v}_{\mathrm{B}}\right)=\mathrm{R} \dot{\mathrm{v}}_{\mathbf{E}}
$$

On the other hand the derivation w.r.t. the body coordinate is: 


$$
\frac{d}{d t_{\mathrm{B}}}\left(\mathrm{v}_{\mathrm{B}}\right)=\dot{\mathrm{v}}_{\mathrm{B}}=\dot{\mathrm{R}} \mathrm{v}_{\mathbf{E}}+\mathrm{R} \dot{\mathrm{v}}_{\mathbf{E}}
$$

From theorem of Coriolis [11]:

$$
\frac{d}{d t_{I}}\left(\mathrm{v}_{B}\right)=\dot{\mathrm{B}_{\mathrm{B}}}+\omega_{\mathrm{B}} \times \mathrm{v}_{\mathrm{B}}
$$

the cross product, is replaced by the dot product of the skew-symmetric matrix form of $\omega_{\mathrm{B}}$ [10] as:

$$
\omega_{\mathrm{B}} \times \mathrm{v}_{\mathrm{B}}=\Omega_{\mathrm{B}} \mathrm{v}_{\mathrm{B}}
$$

where:

$$
\Omega_{\mathrm{B}}=\left[\begin{array}{ccc}
0 & -R & Q \\
R & 0 & -P \\
-Q & P & 0
\end{array}\right]
$$

Comparing Eq. (8) with Eq. (9) and substitute of $v_{B}=R v_{E}$ :

$$
\dot{\mathrm{R}}=-\Omega_{\mathrm{B}} \mathrm{R}
$$

Using equation (5) in the evaluation of equation (11) [12], leads to the equation of Euler angle derivatives as:

$$
\mathbf{\Phi}=\frac{d}{d t}\left[\begin{array}{l}
\phi \\
\theta \\
\psi
\end{array}\right]=\left[\begin{array}{ccc}
1 & \tan \theta \sin \phi & \tan \theta \cos \phi \\
0 & \cos \phi & -\sin \phi \\
0 & \frac{\sin \phi}{\cos \theta} & \frac{\cos \phi}{\cos \theta}
\end{array}\right]\left[\begin{array}{l}
P \\
Q \\
R
\end{array}\right]
$$

Or

$$
\boldsymbol{\Phi}=\xi(\phi) \omega_{\mathrm{B}}
$$

\subsection{Translational Motion Equations}

From Newton's second law of linear momentum one can write:

$$
\mathbf{F}_{\mathrm{B}}+\mathrm{Rmg}=\frac{\mathrm{d}}{\mathrm{dt}_{\mathrm{I}}}\left(\mathrm{m} \mathbf{v}_{\mathbf{B}}\right)
$$

where :

$\mathbf{F}_{\mathrm{B}} \ldots$ the sum vector of the acting forces on the UAV (thrust and aerodynamic forces) expressed in the body coordinate.

$$
\begin{aligned}
\mathbf{F}_{\mathrm{B}} & =\left[\begin{array}{lll}
F_{x} & F_{y} & F_{z}
\end{array}\right]^{T} \\
& =\left[\begin{array}{lll}
0 & 0 & -F_{\text {Thrust }}
\end{array}\right]^{T}
\end{aligned}
$$

g ... the gravitational attraction vector (expressed in the inertial coordinate) due to earth mass

$\mathrm{R}$... the matrix that rotates the $\mathrm{g}$ vector into the body frame

$\mathrm{m}$... mass of the UAV

$\mathbf{V}_{\mathbf{B}} \ldots$ absolute velocity vector of the UAV cg expressed in body frame ( measured with respect to the inertial frame). 
From theorem of Coriolis (9), and substituting in (13), assuming that UAV mass does not change with time, $\dot{\mathrm{m}}=0$, rearranging using (10) leads to:

where :

$$
\dot{v_{\mathrm{B}}}=\frac{1}{\mathrm{~m}} \mathrm{~F}_{B}-\Omega_{\mathrm{B}} \mathrm{v}_{\mathrm{B}}+\mathrm{Rg}
$$

and

$$
\mathrm{g}=\left[\begin{array}{c}
0 \\
0 \\
g_{o}
\end{array}\right]
$$

\subsection{Angular Motion Equations}

The angular acceleration of the UAV can be determined by applying Newton's second law to the rate of change of angular momentum of the UAV, i.e.:

$$
\mathrm{T}_{\mathrm{B}}=\frac{\mathrm{d}}{\mathrm{dt}_{\mathrm{I}}}\left(\mathrm{H}_{\mathrm{B}}\right)
$$

where:

$\mathrm{H}_{\mathbf{B}} \ldots$ the angular momentum vector of the rigid vehicle

$\mathrm{T}_{\mathrm{B}} \ldots \quad$ the net torque acting about the air craft cg

where:

$$
\mathrm{T}_{\mathrm{B}}=\left[\begin{array}{l}
\mathrm{L} \\
\mathrm{M} \\
\mathrm{N}
\end{array}\right]
$$
L ... rolling moment
$\mathrm{M}$ pitching moment
$\mathrm{N}$... yawing moment

The infinitesimal translational momentum of an element mass $\delta m$ with position vector $\mathbf{r}$ will be:

$$
\delta(\text { momentum })=\left(\omega_{\mathrm{B}} \times \mathrm{r}\right) \delta \mathrm{m}
$$

Then the angular momentum of this particle is:

$$
\delta \mathrm{H}_{\mathrm{B}}=\left(\mathrm{r} \times\left(\omega_{\mathrm{B}} \times \mathrm{r}\right)\right) \delta \mathrm{m}
$$

where:

$\omega_{\mathbf{B}}$ the absolute body coordinate angular velocity

Integrating equation (16) leads to:

$$
\omega_{\mathrm{B}}=\mathrm{pi}+\mathrm{Qj}+\mathrm{Rk}
$$

where:

$$
\mathrm{H}_{\mathrm{B}}=\mathrm{J} \omega_{\mathrm{B}}
$$

$\mathrm{J}$... the inertia matrix of the UAV rigid body

Because of UAV symmetry only $I_{x x}, I_{y y}$, and $I_{z z}$ have values, ie:

$$
\mathrm{J}=\left[\begin{array}{ccc}
I_{x x} & 0 & 0 \\
0 & I_{y y} & 0 \\
0 & 0 & I_{z z}
\end{array}\right]
$$

Using (15) and (17) after rearrangement using (10): 
where

$$
\dot{\omega}_{\mathrm{B}}=-\mathrm{J}^{-1} \Omega_{\mathrm{B}} \mathrm{J} \omega_{\mathrm{B}}+\mathrm{J}^{-1} \mathrm{~T}_{\mathrm{B}}
$$

$$
\mathbf{J}^{-1}=\left[\begin{array}{ccc}
\frac{1}{I_{x x}} & 0 & 0 \\
0 & \frac{1}{I_{y y}} & 0 \\
0 & 0 & \frac{1}{I_{z z}}
\end{array}\right]
$$

Now assymbling the equations (6), (12), (14), and (18) to get the state space represintation

$$
\begin{aligned}
& \frac{d}{d t}\left[\begin{array}{l}
v_{B x} \\
v_{B y} \\
v_{B z}
\end{array}\right]= {\left[\begin{array}{c}
R v_{B y}-Q v_{B z}-g_{0} \sin \theta \\
-R v_{B x}+P v_{B z}+g_{0} \sin \varphi \cos \theta \\
Q v_{B x}-P v_{B y}-\frac{F_{T h r u s t}}{M}+g_{0} \cos \varphi \cos \theta
\end{array}\right] } \\
& \frac{d}{d t}\left[\begin{array}{l}
\omega_{x} \\
\omega_{y} \\
\omega_{z}
\end{array}\right]=\left[\begin{array}{c}
\frac{R I_{y} \omega_{y}}{I_{x}}-\frac{Q I_{z} \omega_{z}}{I_{x}}+\frac{L}{I_{x}} \\
-\frac{R I_{x} \omega_{x}}{I_{y}}+\frac{P I_{z} \omega_{z}}{I_{y}}+\frac{M}{I_{y}} \\
\frac{Q I_{x} \omega_{x}}{I_{z}}-\frac{P I_{y} \omega_{y}}{I_{z}}+\frac{N}{I_{z}}
\end{array}\right]
\end{aligned}
$$

And the noticed output is:

$$
\frac{d}{d t}\left[\begin{array}{l}
\phi \\
\theta \\
\psi
\end{array}\right]=\left[\begin{array}{c}
P+Q \tan \theta \sin \varphi+R \tan \theta \cos \varphi \\
Q \cos \varphi-R \sin \varphi \\
Q \frac{\sin \varphi}{\cos \theta}+R \frac{\cos \varphi}{\cos \theta}
\end{array}\right]
$$

$\frac{d}{d t}\left[\begin{array}{c}P_{x} \\ P_{y} \\ P_{z}\end{array}\right]=\left[\begin{array}{c}(\cos \theta \cos \psi) v_{B x}+(-\cos \varphi \sin \psi+\sin \varphi \sin \theta \cos \psi) v_{B y}+(\sin \varphi \sin \psi+\cos \varphi \sin \theta \cos \psi) v_{B z} \\ (\cos \theta \sin \psi) v_{B x}+(\cos \varphi \cos \psi+\sin \varphi \sin \theta \sin \psi) v_{B y}+(-\sin \varphi \cos \psi+\cos \varphi \sin \theta \sin \psi) v_{B z} \\ -\sin \theta \cdot v_{B x}+\sin \varphi \cos \theta \cdot v_{B y}+\cos \varphi \cos \theta \cdot v_{B z}\end{array}\right]$

\section{Building the 3-D CAD Model}

In order to evaluate the mass and inertia of the UAV needed in the simulation, a 3-D model must be constructed. The model was built using Autodesk Inventor ${ }^{\circledR}$ software.

At first each element of the UAV was drawn separately, and then assembled to form the entire UAV, [13]. The assembled UAV is shown in Fig.3.

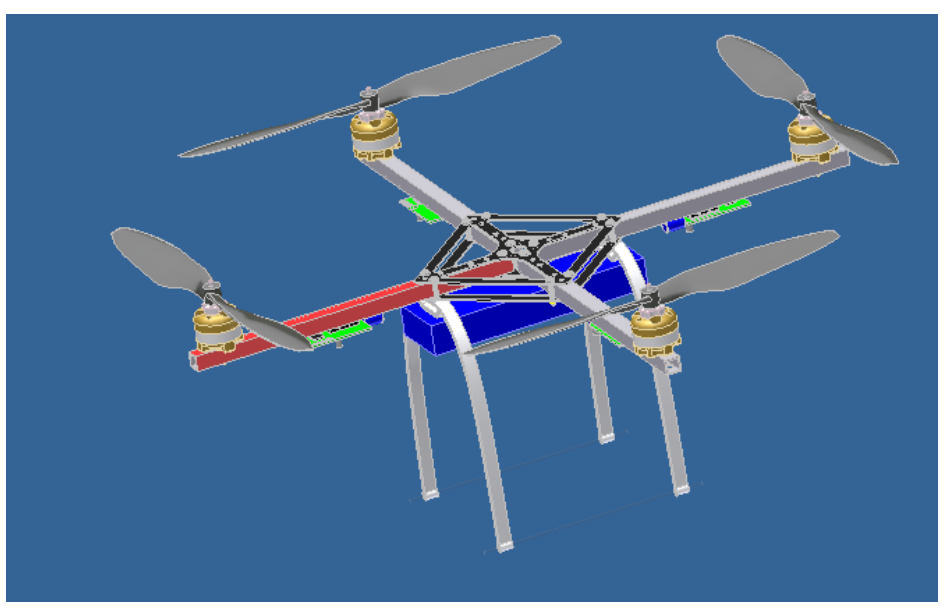

Fig.3. CAD model of the UAV 
After that the model mass and mass moment of inertia are introduced in Table 1

Table 1: UAV mass and mass moment of inertia

\begin{tabular}{lcc}
\hline \hline Total mass & & $0.853 \mathrm{~kg}$ \\
\hline \multirow{3}{*}{ Mass moment of inertia } & $\mathrm{I}_{\mathrm{xx}}$ & $7141.407 \mathrm{~kg} \mathrm{~mm}^{2}$ \\
& $\mathrm{I}_{\mathrm{yy}}$ & $7830.371 \mathrm{~kg} \mathrm{~mm}^{2}$ \\
& $\mathrm{I}_{\mathrm{zz}}$ & $13757.579 \mathrm{~kg} \mathrm{~mm}^{2}$ \\
\hline
\end{tabular}

\section{Motor Propeller System Modeling}

The only affecting external force taken into account is the thrust delivered from the motorpropeller unit in the UAV, assuming indoor flaying condition and traveling at low speed (neglect the wind effect, and aerodynamic drag). Many investigations are made on this part concerned mainly on the evaluation of a relationship between the electric input power (in other words, motor shaft rotation speed, and torque) and the output thrust from the propeller fixed at the motor shaft [14]. In a matter of fact this assumptions indicate the fuzziness of the quad rotor system.

A test rig has been prepared as shown in Fig. 4.

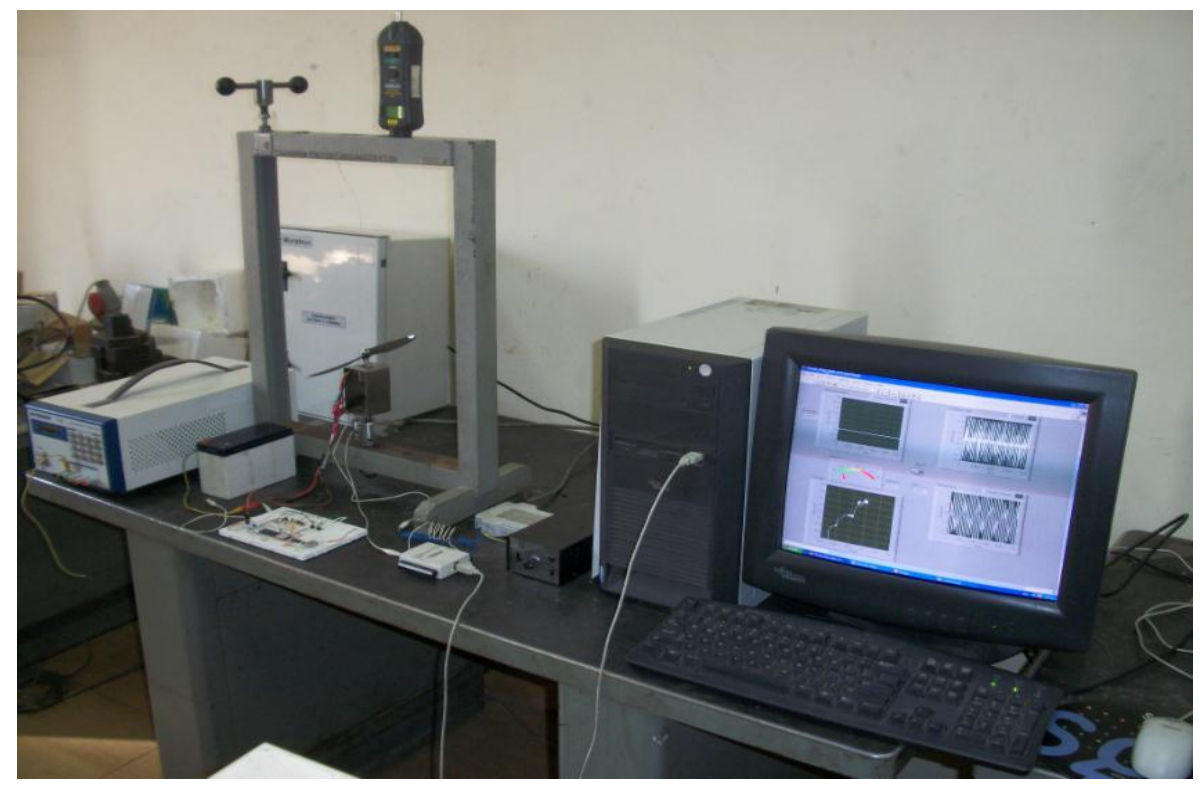

Fig. 4. PWM-Thrust relationship measurement test rig

The motor is controlled using PIC microcontroller by which the motor speed can be decremented up or down by means of Pulse Width Modulation (PWM) signal, where the motor input PWM signal is considered as the control input. At certain motor speed the thrust is measured using a force transducer. The force transducer measured signal is amplified and acquired to a PC.

At each measurement the propeller speed is evaluated using laser tachometer, while the input PWM signal to the motor Electronic Speed Controller (ESC) is recorded throw the data acquisition card. Using Lab View environment, the acquired date are recorded and analyzed. 
Fig. 5 shows measurements of the PWM value vs. thrust of motor (1) (motor order in Fig. 6).

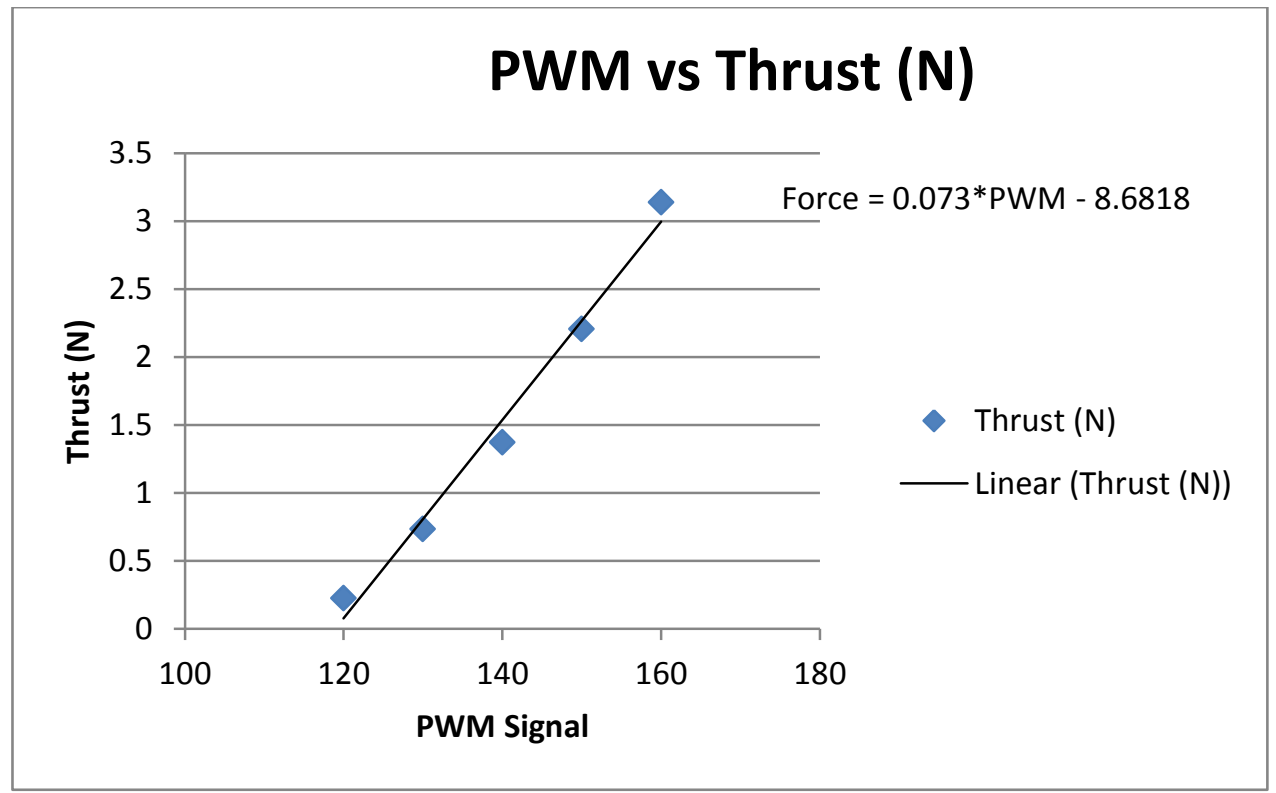

Fig.5. PWM signal vs. motor (1) thrust

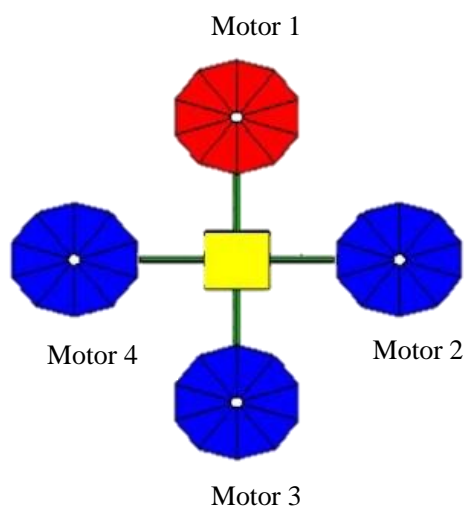

Fig. 6. Motors order as in the simulated model

\section{Building the Matlab/SIMULINK® Model}

The model shown in Fig. 7 consists mainly from Thrust block which calculate the motor thrust as a function of the input signal for each motor. The block output is the control vector $\mathbf{u}$, in other word, the all over system thrust and moments.

System mass and inertia are fed to the model as constant blocks, while the initial condition are assumed to be zeros $\left(\mathrm{X}_{0}=0\right.$ at time $\left.\mathrm{t}=0\right)$.

From the dynamic model of the quad rotor we see some special properties as listed below:

- Rotations are not affected by translations

- System is under actuated

- System has coupling effects

- System is unstable 


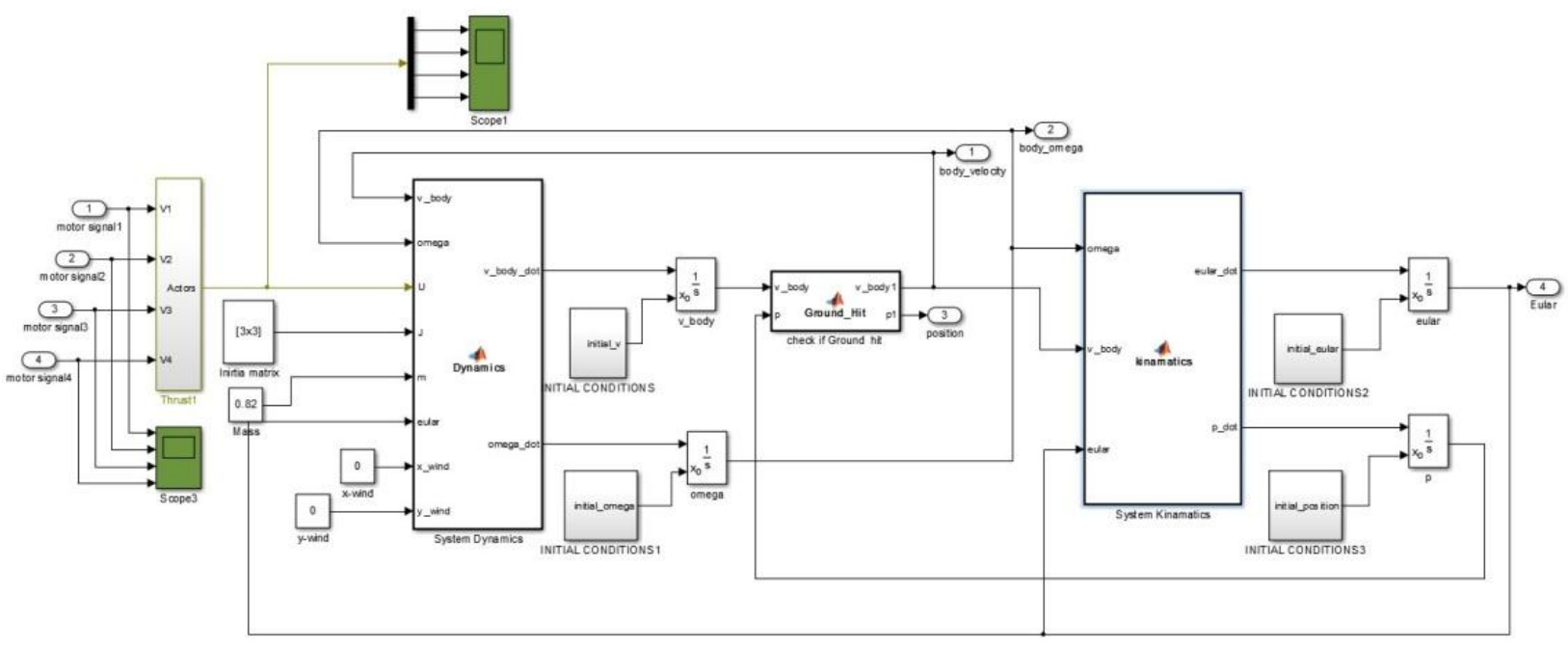

Fig. 7 The quad rotor Simulink model

\section{Fuzzy Controller Design}

Natural language uncertainty and the approximate reasoning mechanism of the human brain can be modeled through the use of fuzzy logic. The knowledge base of a fuzzy system is described by a set of rules as in an expert system. However, the rule computation is performed numerically as in a neural network. This double view (symbolic description and analytic processing) means that fuzzy logic is useful for modeling those systems in which it is difficult to achieve an accurate mathematical behavior [15].

It is worthy to mention that for the purpose of testing the controller behavior, there are some assumption that are already declared in mathematical model formulation part, there is an important assumption that the thrust produced from all the motor-propeller systems is identical, and then when a good controller behavior is reached, the motor's thrust variations, dynamic drag, and the nonlinear relation of control signal (PWM signal ) and thrust force are introduced to the simulation model, so the controller performance is tested prior applying the control methods on the test rig.

\subsection{FUZZY PID Like Controller}

It is well known that conventional proportional-integral-derivative controllers are still one of the most widely adopted methods in industry for various control applications. PID controllers have a number of distinctive advantages such as their simple structure, ease of design, and low cost of implementation in comparison to many other control methods. However, PID controllers might not perform satisfactorily or as desired if the system to be controlled is highly nonlinear or uncertain, or if the control performance specification is very demanding. On the other hand, fuzzy control has long been known for its ability to handle nonlinearities and uncertainties through the use of fuzzy set theory. It is thus believed that a better control system to take advantage of PID control and fuzzy control can be achieved by adequately integrating these two techniques. Considerable effort has been devoted to the course of this development and many significant results have been obtained. The resulting controllers are usually called fuzzy PID controllers [16].

Figure 8 shows the block diagrams of the quad rotor with controllers. 


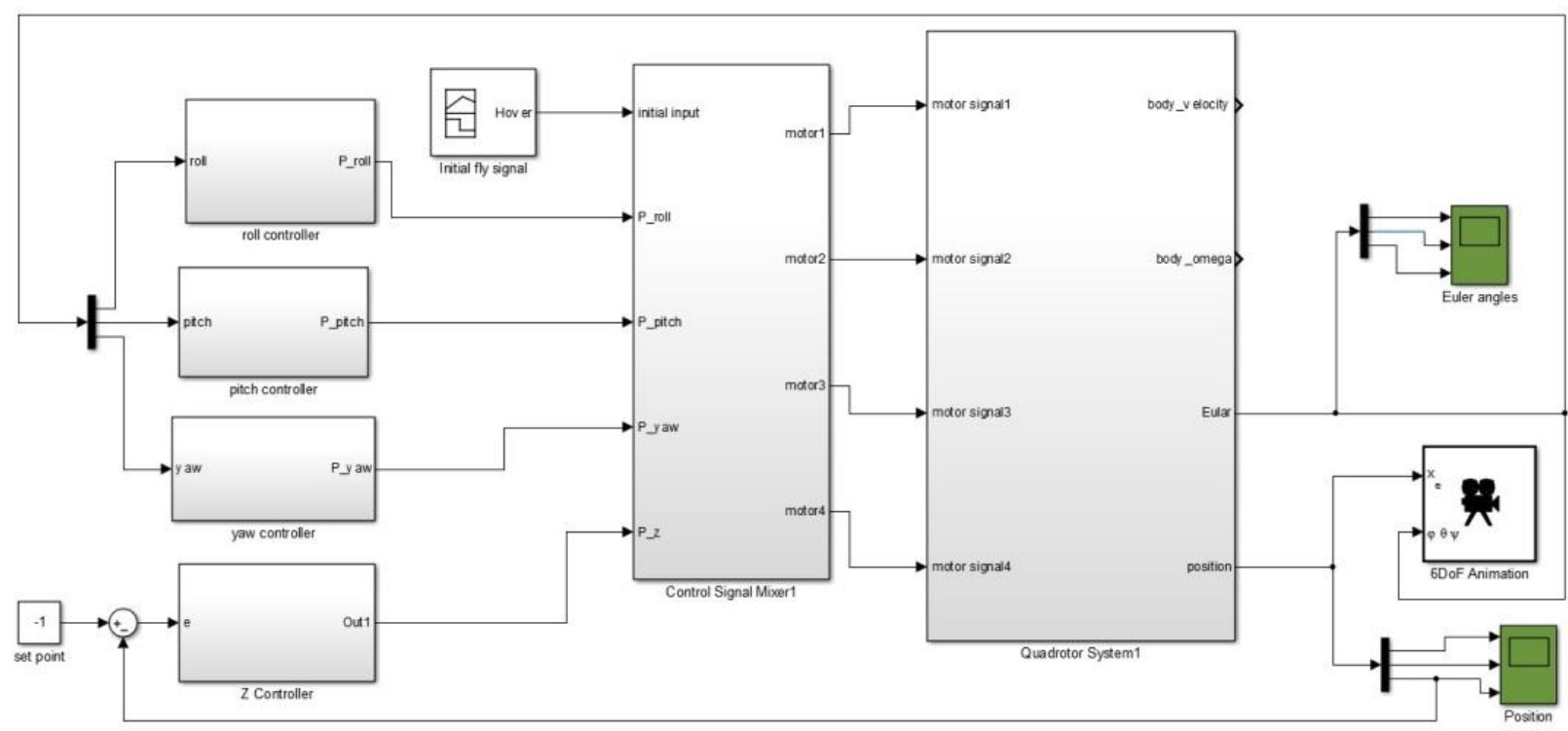

Fig. 8. Quad rotor with altitude, pitch, roll, and yaw controllers

$\mathrm{Z}$ Controller is responsible of bringing the quad rotor to the desired height; notice that in our proposed Flat Earth coordinate the quad rotor flies towards the negative $\mathrm{Z}$ axis (Fig. 2). Roll, pitch, and yaw are controlled by corresponding block in Fig. 8.

\subsubsection{Altitude controller}

As mentioned before, it is Fuzzy PID like type; actually it consists of two separate fuzzy logic controllers: PD like and PI like fuzzy controllers. All of the controllers are designed as mamdani type with max-min composition and with bisector deffuzification method. Fig. 9and 10 shows the input and output membership functions (MF) PD like and PI like fuzzy controllers (error, error derivative and the output controller signal). Also the control surface is presented.

\subsubsection{Roll, pitch and yaw controllers}

As in the altitude controller, each one consists of two fuzzy logic controllers PD and PI like. All of them have the same MF's and rule base as shown in Fig.11 and 12.

For all the cases it was apparent that the PI like controller assist the PD like controller depending on the history of the quad rotor tending to stay above or under the set point.

\section{Results}

First, all the angles kept at zero set point and the desired altitude was fed as step input value of 1 meter. The simulation results of the altitude are shown in Fig.13 (other state variables were zeros).

Then series of desired attitude are introduced to the system, Fig. 14 shows simulation results.

The system output for a series of step inputs is shown in Fig.15 (Euler angles are kept zeros). Secondly, after settling at one meter height, Euler angles are set to different set points; selected results are shown in Fig. 15, 16 and 17. 

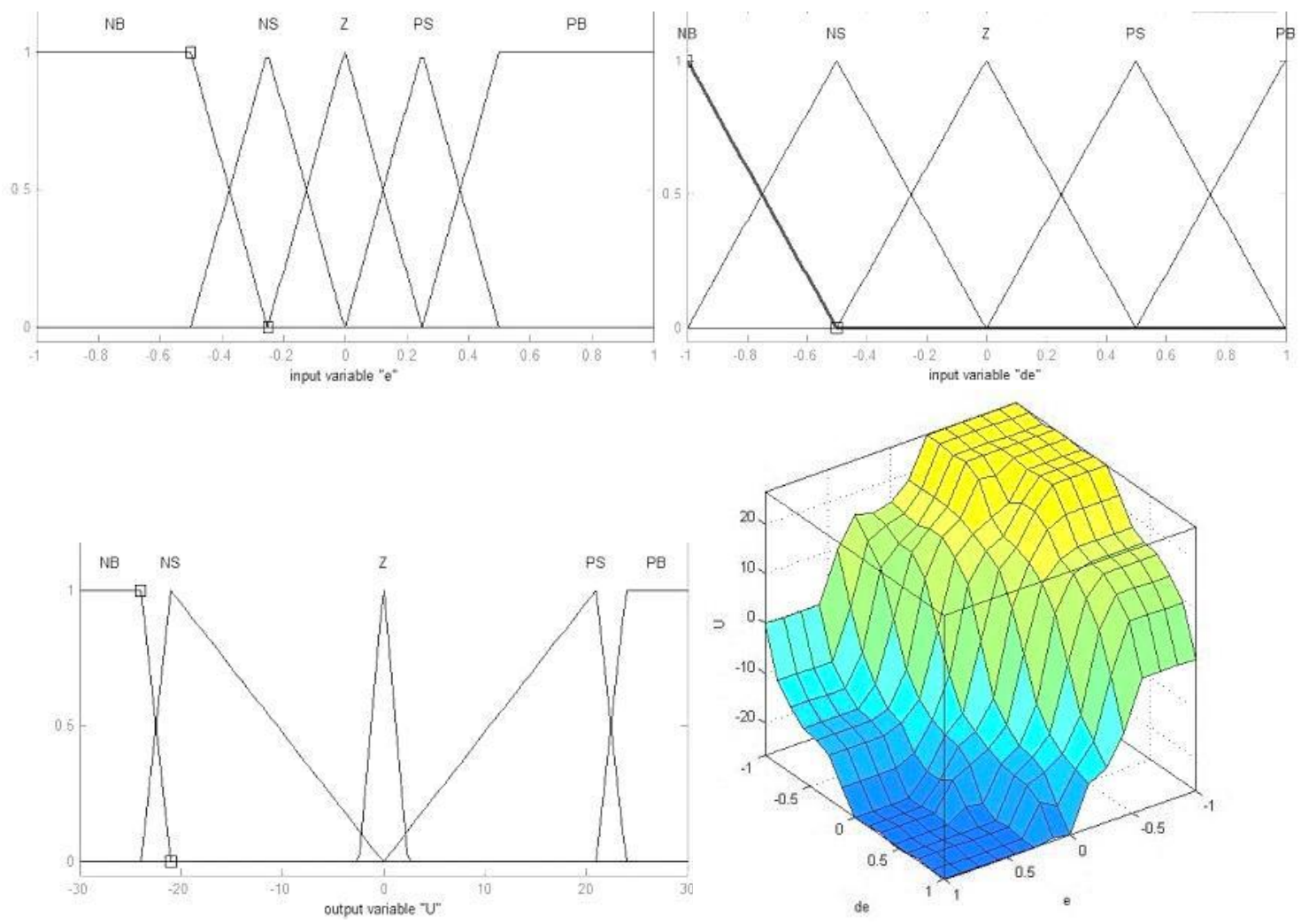

Fig. 9. Fuzzy PD like controller MF and the control surface representation
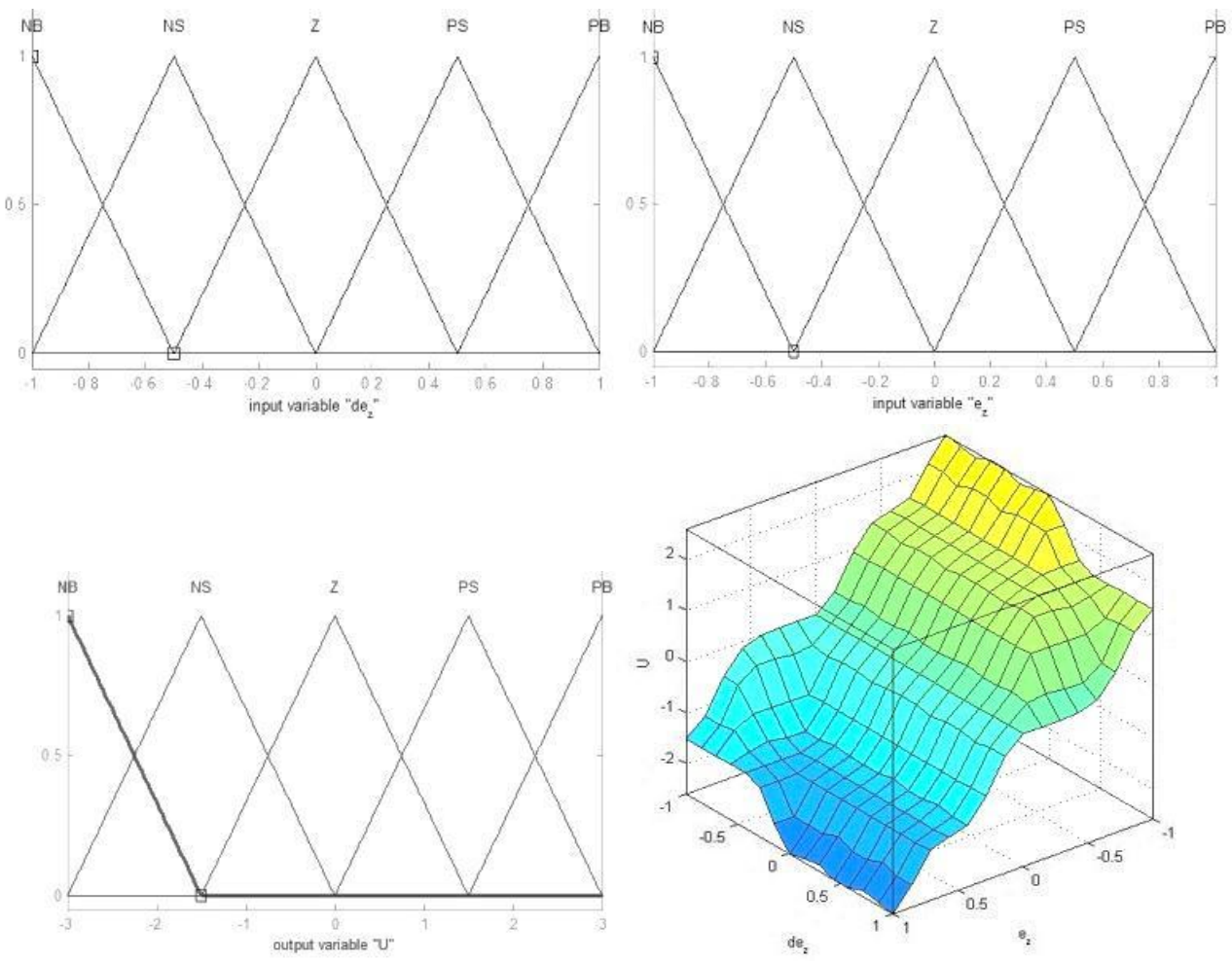

Fig. 10. Fuzzy PI like controller MF and the control surface representation 

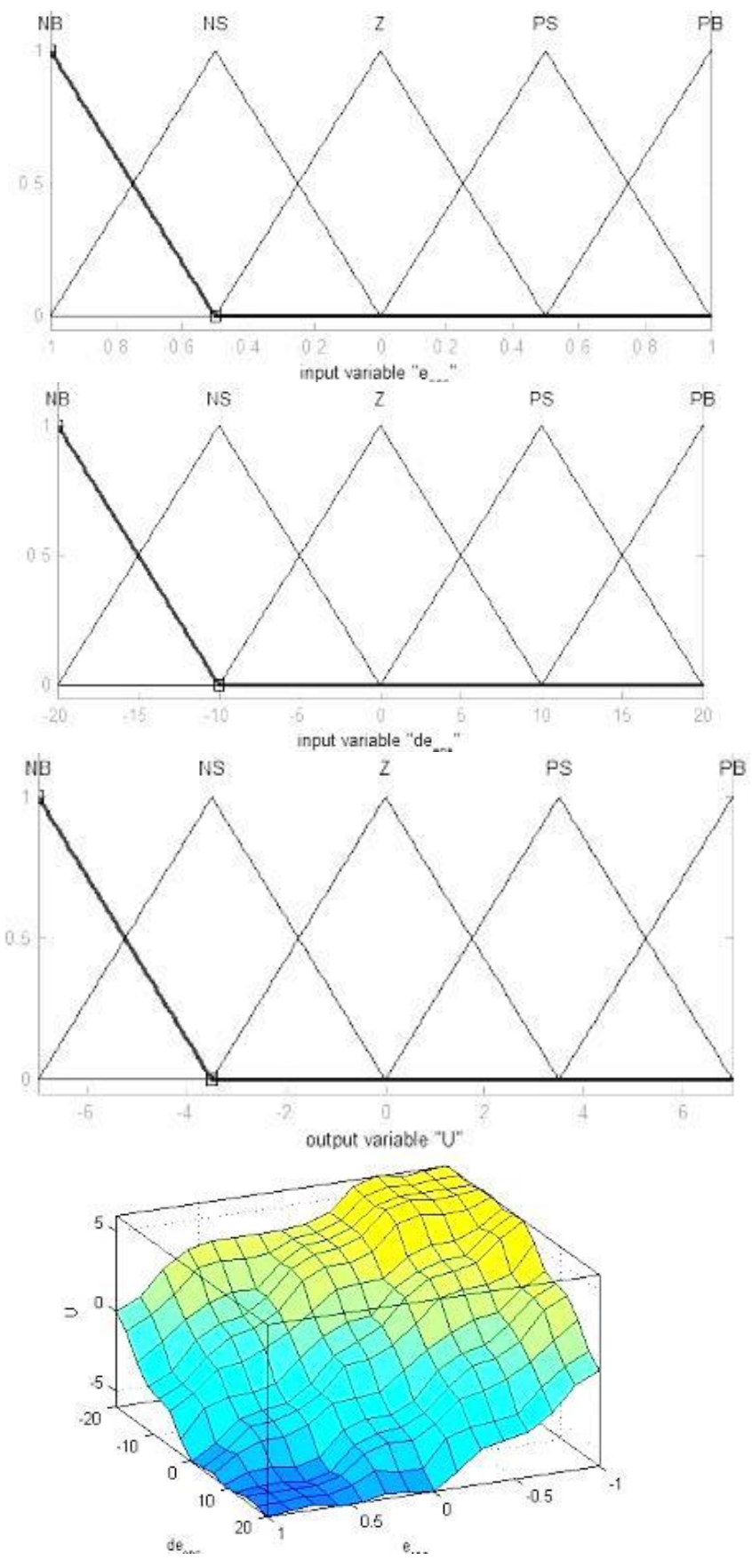

Fig. 11. Fuzzy PD like controller MF and the control surface representation 

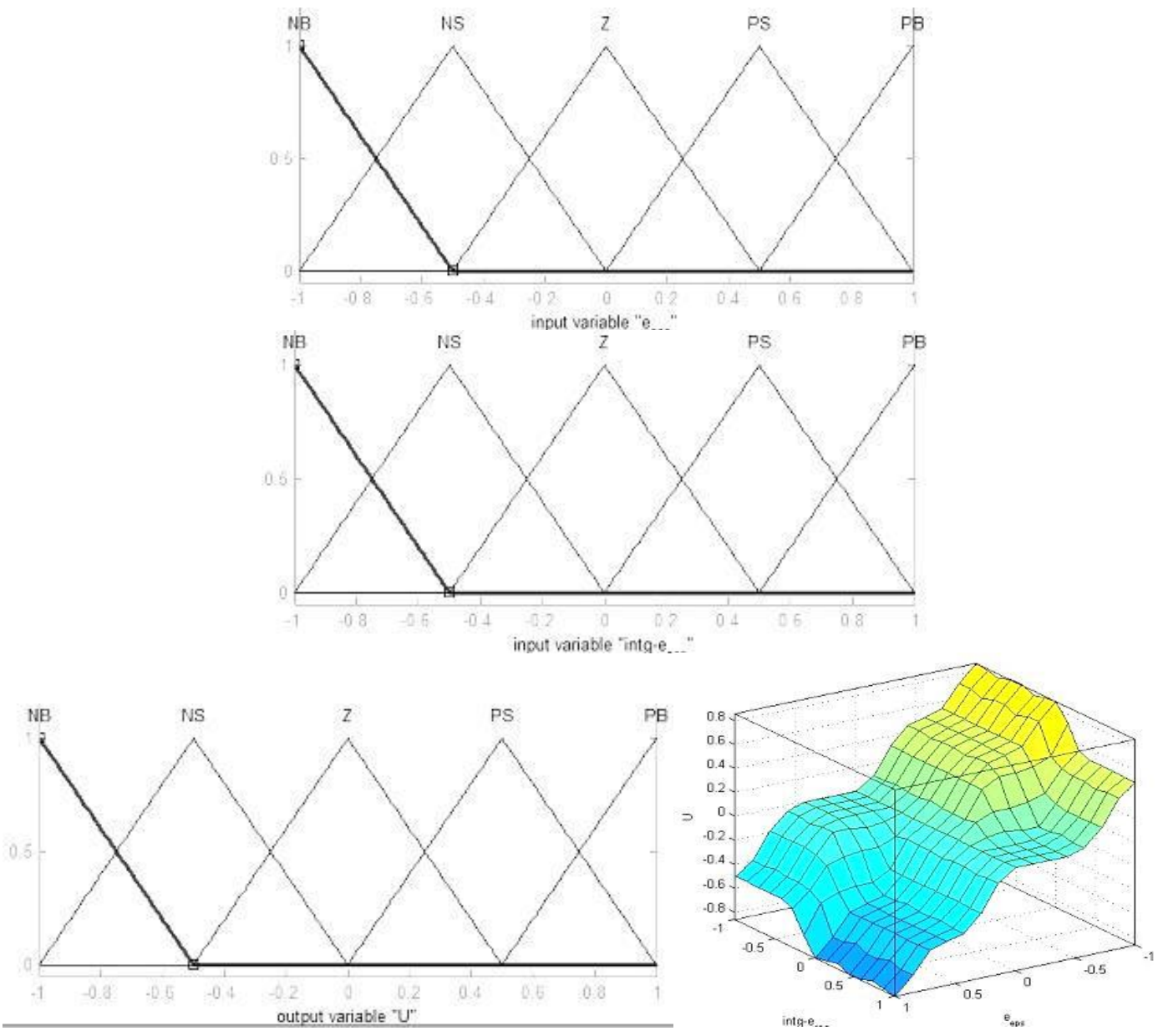

Fig. 12. Fuzzy PI like controller MF and the control surface representation

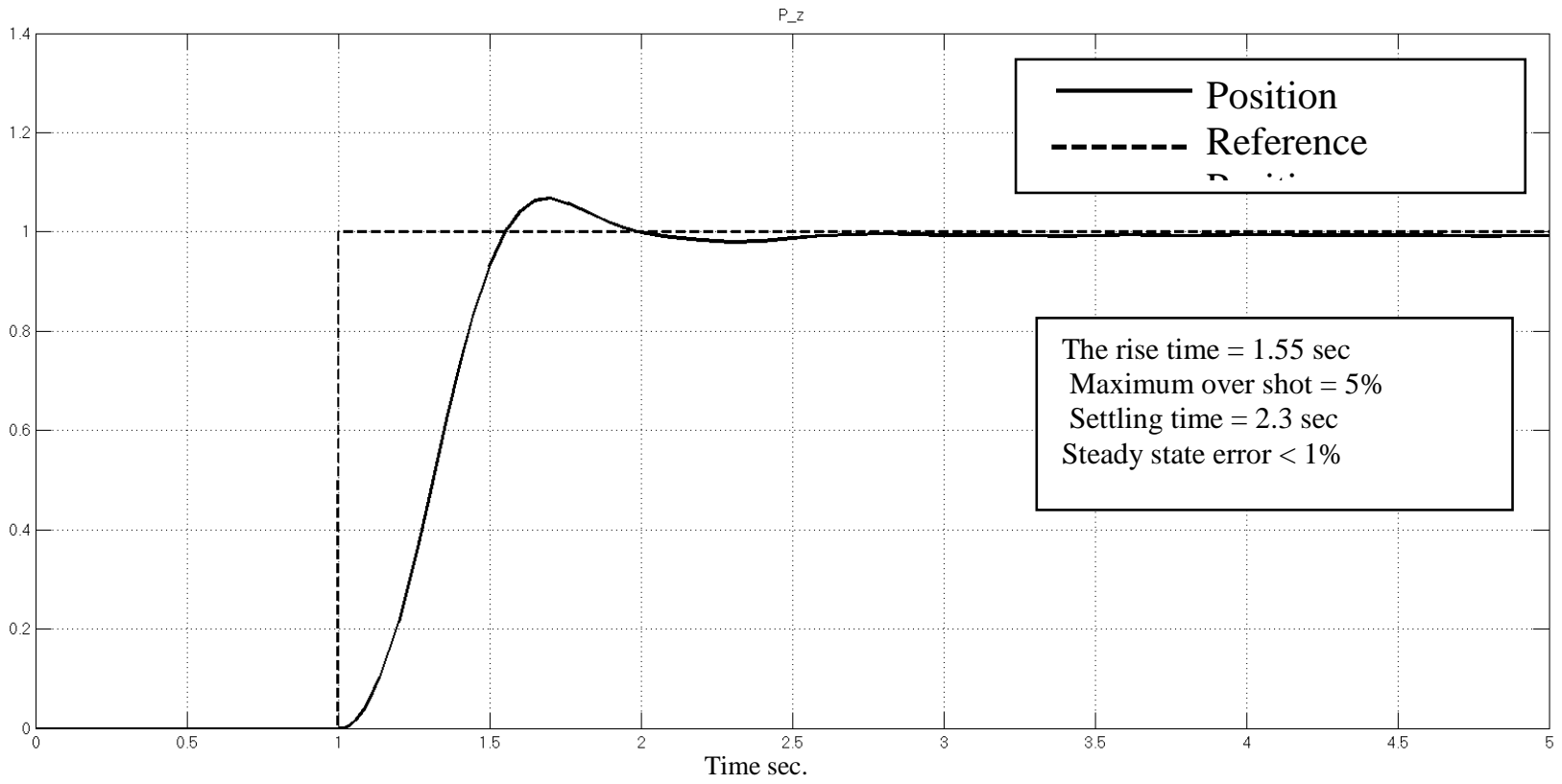

Fig.13. Model output at set point 1 meter height and 0 degree Euler angles 


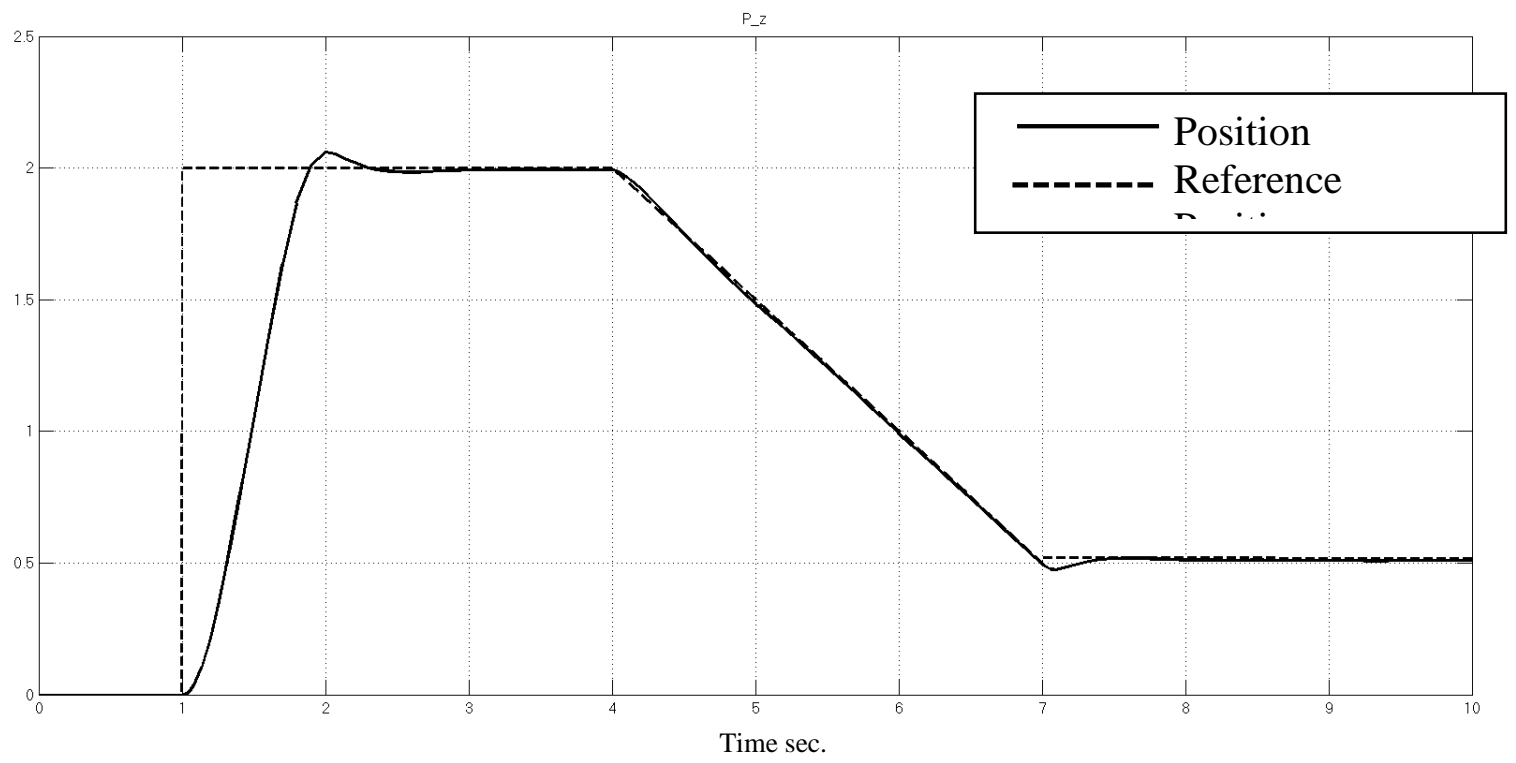

Fig.14. Model output for a series of different inputs and 0 degree Euler angles

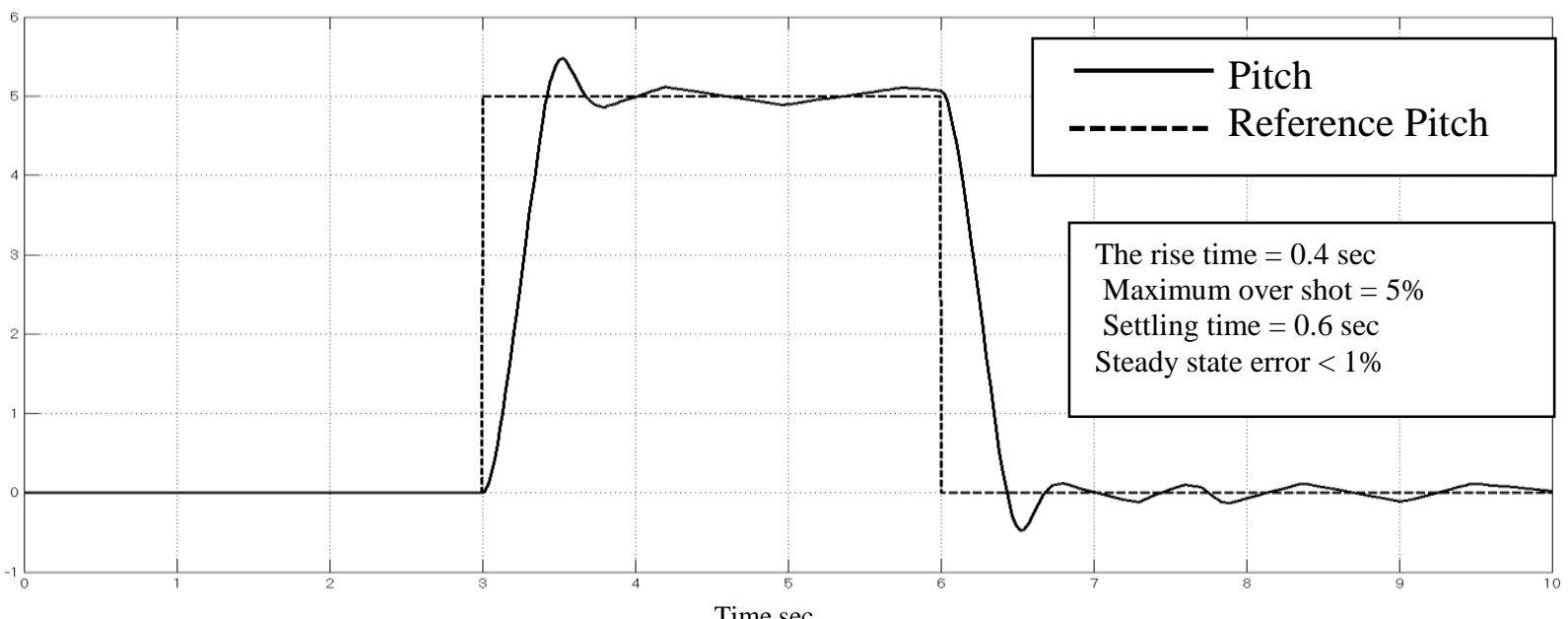

Fig.15 System simulated Euler angles for 5 deg. pitch input signal.

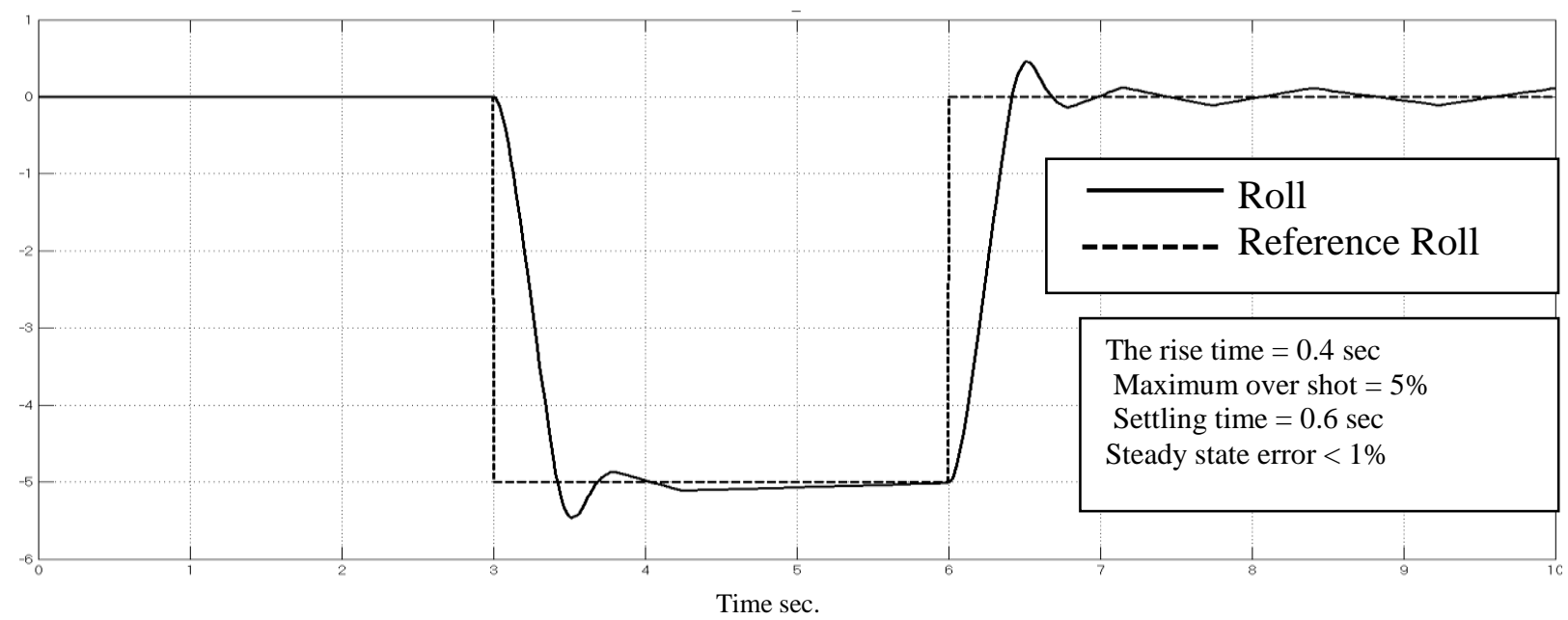

Fig.16. System simulated Euler angles for -5 deg. roll input signal. 


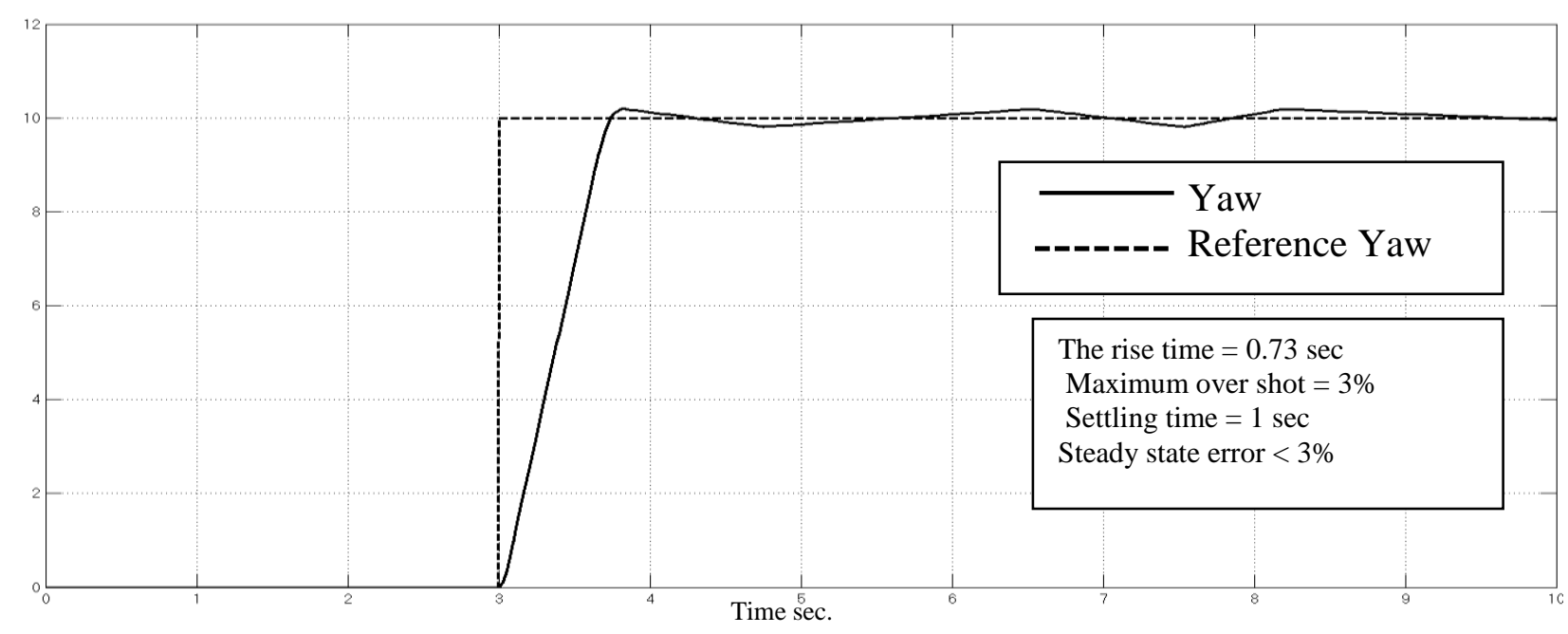

Fig.17. System simulated Euler angles for $10 \mathrm{deg}$. roll input signal.

\section{Discussion}

Results showed that the controllers can effectively manipulate the input variation over the Euler angles and altitude in suitable response time. The altitude control was reached with small over shoot, while the angular control response time was shorter than altitude control and with small over shoot. It was noticed the existence of steady state error that did not exceed $\pm 3 \%$.

\section{Conclusion}

Flexibility and ability to control nonlinear systems had made fuzzy controllers accepted and employed in many fields and applications. Fuzzy PID like controllers were applied to control the altitude and the Euler angles of a quad rotor UAV. In fact controlling Euler angles is indirectly control the remaining two outputs ( $\mathrm{x}$ and y positions). First of all the system outputs were decoupled and fed to each appropriate controller. The overall performance was good enough to be able to perform multiple tasks applied in sequence. With a minimum steady state error, reasonable response time and small over shoot when applying step input, it was noticed the system reaches instability when the altitude set point exceeds 5 meter height. It is recommended to introduce a stabilizer to handle the system stability when the disturbance in one state variable exceeds the existing controllable rang. Also the air drag, wind gust, and any other disturbance should be introduced to the model to examine that the controller could handle the situation.

\section{References}

[1] Kundak, N., \& Mettler, B. , Experimental framework for evaluating autonomous guidance and control algorithms for agile aerial vehicles., in The European control conference 2007(2007): Kos, Greece. p. (pp. 293-300).

[2] Mario Valenti, B. B. F.a. J. P. H., Indoor Multi-Vehicle Flight Testbed for Fault Detection, Isolation, and Recovery. AIAA Guidance, Navigation, and Control Conference. Keystone, USA., 2006.

[3] Waslander, S. L., Hoffman,G. M., Jang, J. S.,\& Tomlin, C. J., Multi-agent quadrotor test bed control design: Integral sliding mode vs. reinforcement learning., in The 2005 IEEE/RSJ international conference on intelligent robots and systems2005: Edmonton, Canada. p. (pp. 3712-3717). 
[4] Bouabdallah, S., \& Siegwart, R., Backstepping and sliding-mode techniques applied to an indoor micro quadrotor., in Proceedings of The 2005 IEEE international conference on robotics and automation2005: Barcelona, Spain. p. 2259-2264.

[5] Koo, T. J., \& Sastry, S. , Output tracking control design of a helicopter model based on approximate linearization., in The 37th IEEE conference on decision and control.1998: Tampa, Florida, USA.

[6] Frazzoli, E., Dahleh, M. A., \& Feron, E. , Trajectory tracking control design for autonomous helicopters using a backstepping algorithm., in American control conference.2000: Chicago, USA.

[7] Mahony, R., \& Hamel, T. , Robust trajectory tracking for a scale model autonomous helicopter., in In Proceedings of 14th International Journal of Robustand Nonlinear Control, 2004. p. 1035-1059.

[8] Dzul, A., Hamel, T., \& Lozano, R., Modelisation et Commande Non Lineaire pour un Helicoptere Birotor Coaxial., in Proceedings of 37 Journal Europeen des Systemes Automatises, 2003. p. 1277-1295.

[9] B. L. Stevens, F. L. L., Aircraft Control and Simulation. 10th ed1992: John Wiley \& Sons, Inc.

[10] ZIPFEL, P.H., Modeling and Simulation of Aerospace Vehicle Dynamics. 5th ed 2005: American Institute of Aeronautics and Astronautics.

[11] Woodhouse, N. M. J., Introduction to Analytical Dynamics. 2nd ed 2009: Springer.

[12] Valavanis, K. P., Advances in Unmanned Aerial Vehicles 2007: Springer.

[13] MikroKopter Official site. Available from: http://www.mikrokopter.de/ucwiki/en/MikroKopter.

[14] MARTíNEZ, V.M., Modelling of the Flight Dynamics of a Quadrotor Helicopter, in School of Engineering 2007, Cranfield University.

[15] Kosko, B., Neural networks and fuzzy systems, A Dynamical Systems Approach to Machine Intelligence1992: Prentice-Hall Int.

[16] Feng, G., Analysis and Synthesis of Fuzzy Control Systems. Automation And Control Engineering, ed. P.D. Frank L. Lewis, Shuzhi Samge, Ph.D.2011: CRC press. 